\title{
A Novel and Simple Method of Insolubilization of Ovomucoid in Cookies Prepared from Batter Containing Egg White
}

\author{
Yasuko KaTO, Kimiko SugINOHARA and Miyuki FuJIWARA \\ Department of Clinical Nutrition, Medical Professions, Kawasaki University of Medical Welfare, 288 Matsushima, Kurashiki-City, Okayama \\ 701-0193, Japan
}

Received May 26, 2000; Accepted October 3, 2000

\begin{abstract}
Heat stable ovomucoid (OM) is a major allergenic protein of chicken eggs, which are widely used in wheat flour processed food. PBS soluble OM remained in the cookies prepared by the usual method. A procedure for insolubilizing OM in batter was designed for cookies supplemented with egg white. Immunoblotting and ELISA competitive inhibition using rabbit anti-OM serum were used to analyze soluble OM in the cookies. PBS soluble OM remained both in the batter and the dough as observed in control egg white solution. Soluble OM in the cookies made from batter baked at $180^{\circ} \mathrm{C}$ for 8 min decreased to about one-tenth of the batter, while it decreased to almost nothing in bread made from dough baked at $180^{\circ} \mathrm{C}$ for $8 \mathrm{~min}$. When the batter was mixed for 15 min before baking at $180^{\circ} \mathrm{C}$ for 12 min, PBS soluble OM disappeared in the cookies as in bread. OM in the cookies was soluble with SDS+2-ME solution, but with neither the PBS nor SDS solution. This suggests that a disulfide exchange reaction between OM and wheat components is induced in the cookies. Both mixing and baking time of batter played an important role in the elimination of PBS soluble OM in the cookies. This simple method is useful for insolubilization of OM in processed foods made from batter supplemented with egg white.
\end{abstract}

Keywords: insolubilization, ovomucoid, egg white, wheat flour, batter, dough

Allergens in foods are mostly proteins, and major allergenic proteins have been isolated from milk, egg, soybean, wheat, etc. Many food allergens identified in water and salt soluble fractions are relatively low molecular weight proteins or glycoproteins and are often resistant to heat denaturation and proteolytic digestion (Taylor, 1980; Matsuda et al., 1982). Ovomucoid (OM) is a major allergenic protein in chicken egg white, (Langeland, 1982a, b; Hoffman, 1983) and is even soluble and antigenic in shelled eggs boiled for $1 \mathrm{~h}$ (Gu et al., 1986), indicating that OM is not rendered insoluble by heating in the presence of other egg white proteins.

Chicken eggs are widely used in processed foods, especially wheat flour foods such as bread and cookies, but have been little examined for their soluble antigenic proteins in these foods. We reported a remarkable decrease in soluble antigenic OM in bread supplemented with egg white during the process of breadmaking (Kato et al., 1997). The effect of wheat gluten on the heatinduced insolubilization of OM was compared with that of soybean protein and milk casein. It was found that OM was easily rendered insoluble by heating in the presence of gluten but not of casein (Kato et al., 2000). This result suggested that wheat gluten might lead to the disappearance of soluble OM through disulfide exchange in the process of baking.

In this report, cookies made from a batter of soft wheat flour, which includes egg white, are used as a model for wheat flour processed food. Our interesr is that OM is insolubilized in the process of creating these cookies through the interaction between $\mathrm{OM}$ and gluten. Consequently, the presence of PBS soluble OM was compared in cookies and bread baked from batter or dough

E-mail: kato@mw.kawasaki-m.ac.jp of soft flour supplemented with egg white, respectively.

\section{Materials and Methods}

Preparation of cookies or bread, and their soluble protein fractions Soft wheat flour used for cookies or bread was a product of Nisshin Mills Co., Ltd. (Tokyo). The other ingredients were sugar, butter and salt.

For cookie making, fresh egg white (110 g, 28\% to total ingredients) and soft flour (120 g) were added to a mixture of butter (90 g) and sugar (70 g) and were thoroughly mixed. The batter sample was divided into small and flat pieces $(7 \mathrm{~g})$ and baked at various temperatures and times in an oven range.

For bread making, soft flour, fresh egg white $(25 \%$ of total ingredients) and other ingredients (instant dry yeast, sugar, skim milk powder, salt and water) were mixed at a ratio of 140 : $63: 49$, and kneaded for $35 \mathrm{~min}$ at $450 \mathrm{rpm}$ using an electric kneader (Taisho Denki Co. Ltd., Kusatsu). The resulting dough was fermented for $150 \mathrm{~min}$ in a chamber (Yamato Scientific Co., Ltd., Model IG-43H.M., Tokyo) maintained at $30^{\circ} \mathrm{C}$ and $75 \%$ $\mathrm{RH}$ (relative humidity), then punched and divided into small pieces $(50 \mathrm{~g})$, followed by a second fermentation at $38^{\circ} \mathrm{C}$ and $85 \% \mathrm{RH}$ until the loaf volume reached 2.5 times the original bulk. The fermented dough was baked at $180^{\circ} \mathrm{C}$ for 8 min unless otherwise noted.

Each sample $(0.364 \mathrm{~g})$ was suspended in $1 \mathrm{ml}$ of phosphate buffered saline of $\mathrm{pH} 7.4$ (PBS), and homogenized with a vortex mixer for $1 \mathrm{~min}$ at the maximum speed (Vortex Genie Scientific Industries, INC, Bohemia, NY) and subsequently ultrasonicated for $15 \mathrm{~min}(100 \mathrm{~W}, 39 \mathrm{kHz})$. Each suspension was kept overnight at $4^{\circ} \mathrm{C}$ and then centrifuged at $16,000 \times g$ for $20 \mathrm{~min}$ to remove the insoluble materials. The supernatant was subjected to analy- 
sis. Proteins were extracted with $4 \%$ sodium dodecyl sulfate (SDS), and 4\% SDS containing 10\% 2-mercaptoethanol $(\mathrm{SDS}+2-\mathrm{ME})$ from cookies baked at $180^{\circ} \mathrm{C}$ for $12 \mathrm{~min}(0.346$ g). These SDS or SDS+2-ME extracts were heated for $5 \mathrm{~min}$ in boiled water, then directly used for the SDS-polyacrylamide gel electrophoresis (SDS-PAGE) and immunoblotting analyses.

SDS-PAGE and immunoblotting Proteins were first separated by SDS-PAGE in $12.5 \%$ acrylamide gel according to the method of Laemmli (1970). One sheet of the gel was stained with Coomassie Brilliant Blue (CBB) R-250, and a second gel was used for immunoblotting. The proteins separated by SDSPAGE were transferred electrophoretically onto a nitrocellulose sheet ( $0.45 \mathrm{~mm}$, Advantec Toyo, Tokyo) by the method of Towbin et al. (1979). The nitrocellulose sheet was incubated overnight at $4^{\circ} \mathrm{C}$ with $3 \%$ bovine serum albumin (BSA) in tris buffered saline of $\mathrm{pH} 7.5$ containing $0.02 \%$ Tween-20 (TBST). After being washed with TBST, the sheet was incubated at $37^{\circ} \mathrm{C}$ for $2 \mathrm{~h}$ in a mixture of $5 \mathrm{ml}$ of $1 \%$ BSA in TBST and $5 \mu \mathrm{l}$ of a rabbit anti-OM serum. It was then incubated at $37^{\circ} \mathrm{C}$ for $1 \mathrm{~h}$ with a $10^{-4}$ fold diluted peroxidase-conjugated goat anti-rabbit $\mathrm{IgG}$ antibody (Cappel Laboratories, Aurora, $\mathrm{OH}$ ) with 1\% BSA/

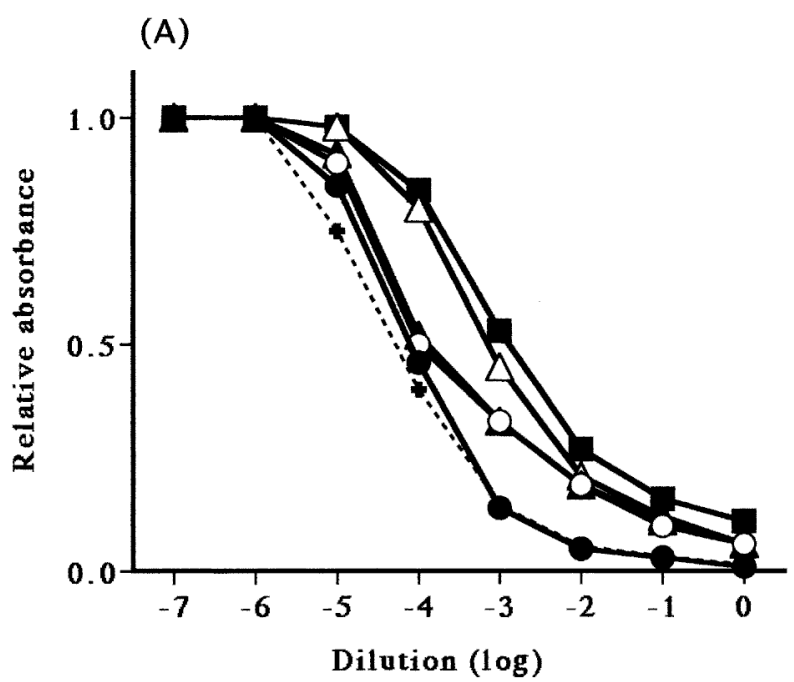

(B)

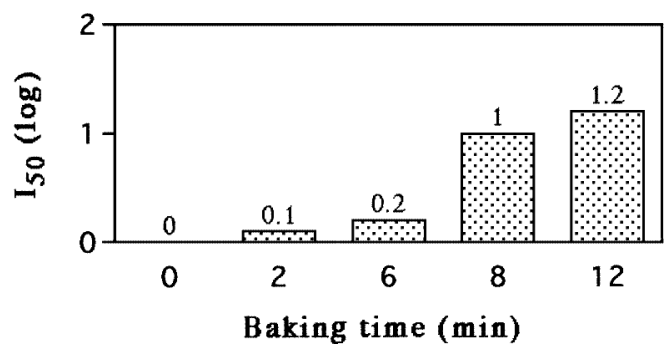

Fig. 1. ELISA competitive inhibition for antigenic OM in the PBS extracts of batter and cookies baked for various times. The relative absorbance is given as the ratio of the absorbance at $492 \mathrm{~nm}$ to the reference, which did not inhibit the reaction between the plate-coated OM and anti OM serum. The PBS-soluble fractions were extracted from the batter $(\bullet)$ and cookies baked for $2(\circ), 6(\boldsymbol{\Delta}), 8(\triangle)$ or $12 \mathrm{~min}(\boldsymbol{\square})$ at $180^{\circ} \mathrm{C}(\mathrm{A})$. EW solution (dotted line) was prepared by replacing other ingredients in batter with the same amount of PBS. The relative absorbance value is given as 1.0 against an absorbance value of 0.917 at $492 \mathrm{~nm}$. $\mathrm{I}_{50}$ means the OM in the sample as the amount $(\log )$ required to attain $50 \%$ inhibition of the reaction between OM and anti OM serum. The $\mathrm{I}_{50}$ value of each sample was compared to batter $(=0)(B)$.

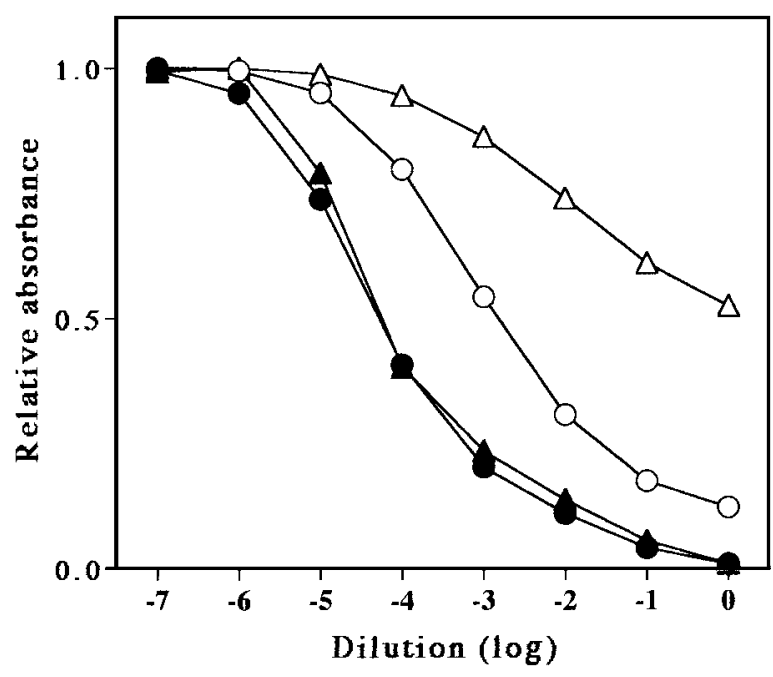

Fig. 2. Comparison of antigenic OM in the PBS extracts of bread and cookie analyzed with ELISA competitive inhibition. The PBS-soluble fractions were extracted from the dough $(\boldsymbol{\Delta})$, batter $(\bullet)$, bread $(\triangle)$, and cookie $(\bigcirc)$. Bread and cookies were baked at $180^{\circ} \mathrm{C}$ for $8 \mathrm{~min}$. The experimental conditions are the same as shown in the legend of Fig. 1.

TBST. The protein bands reactive to the specific antiserum were thereafter activity-stained for peroxidase using 4-chloro-1-naphthol (Bio Rad Laboratories, Hercules, CA).

Enzyme-linked immunosorbent assay (ELISA) competitive inhibition The antigenic activity of OM in samples was evaluated by the competitive inhibition analyses of ELISA (Engvall \& Perlman, 1971; Matsuda et al. 1983) using rabbit anti-OM serum. One hundred microliters of OM solution $(1 \mu \mathrm{g} / \mathrm{ml})$ was added to each well of flat-bottomed microtiter plates, and incubated for $3 \mathrm{~h}$ at $37^{\circ} \mathrm{C}$, then washed with PBS-T (phosphate buffer saline containing $0.05 \%$ of Tween 20). One percent of BSA/ PBS-T solution was added to each well and incubated for $30 \mathrm{~min}$ at $37^{\circ} \mathrm{C}$. Fifteenth microliters of competitors, PBS extract from sample, was graduatedly diluted with $135 \mu$ l of rabbit anti-OM serum in $1 \%$ of BSA/PBS-T solution $\left(10^{-4}\right)$, applied to the wells after washing with PBS-T twice, and incubated for $3 \mathrm{~h}$ at $37^{\circ} \mathrm{C}$. Each well was washed with PBS-T four times. One hundred microliters of peroxidase conjugated goat anti-rabbit IgG (DAKO Co., Ltd., Glostrup. Denmark) in 1\% of BSA/PBS-T solution $\left(10^{-4}\right)$ was added to each well and incubated for $1 \mathrm{~h}$ at $37^{\circ} \mathrm{C}$. After washing each well with PBS-T three times, $100 \mu \mathrm{l}$ of $o$-phenylenediamine in citrate-phosphate buffer $(0.4 \mathrm{mg} / \mathrm{ml})$ containing $0.03 \%$ of $\mathrm{H}_{2} \mathrm{O}_{2}$ was added to each well and the reaction was stopped with of $50 \mu \mathrm{l}$ of $\mathrm{H}_{2} \mathrm{SO}_{4}$ solution $(2.5 \mathrm{~mol} / \mathrm{l})$ after 20 min at RT. The color development of the well was photometrically measured at $492 \mathrm{~nm}$.

\section{Results and Discussion}

Pieces of batter of similar size were baked at $100^{\circ} \mathrm{C}$ or $120^{\circ} \mathrm{C}$ for 2 to $30 \mathrm{~min}$ and at $150^{\circ} \mathrm{C}$ or $180^{\circ} \mathrm{C}$ for 2 to $12 \mathrm{~min}$. The $\mathrm{OM}$ in soluble fractions from cookie samples was examined by immunoblotting using rabbit anti $\mathrm{OM}$ antibody. PBS-extractable $\mathrm{OM}$ in cookies baked below $150^{\circ} \mathrm{C}$ was clearly detected on the blotting sheet (data not shown). The extraction efficiencies of soluble $\mathrm{OM}$ from cookies baked at $180^{\circ} \mathrm{C}$ for 2 to $12 \mathrm{~min}$ were compared by ELISA competitive inhibition analysis (Fig.1-A), 
(A)

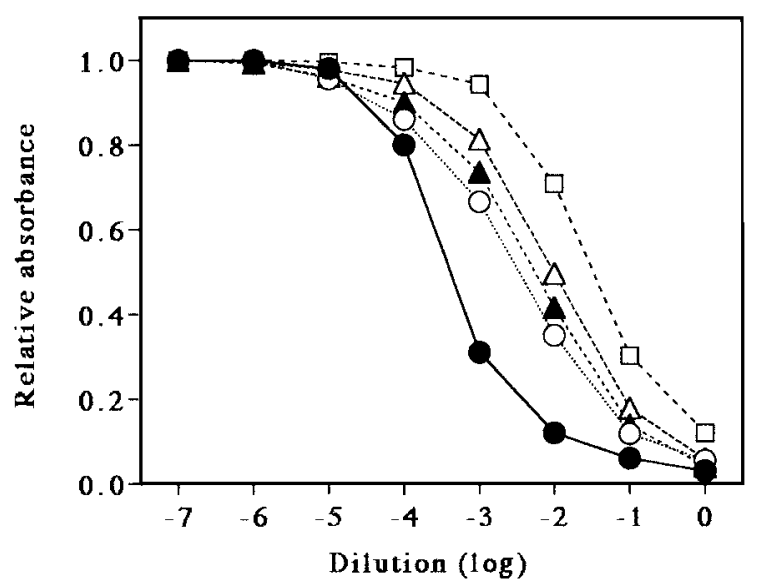

(B)

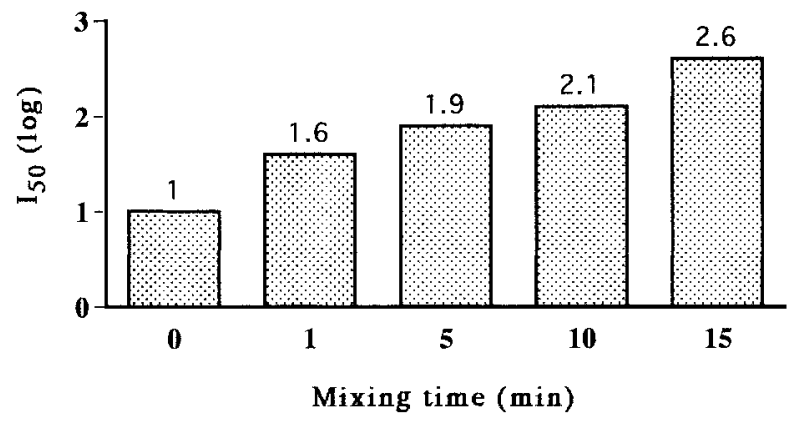

Fig. 3. Effect of mixing time on antigenic OM in the PBS extracts of cookies analyzed with ELISA competitive inhibition. Batter was mixed for zero $(\bullet), 1(\bigcirc), 5(\Delta), 10(\triangle)$, or $15 \mathrm{~min}(\square)$ using a hand mixer, followed by baking at $180^{\circ} \mathrm{C}$ for $8 \mathrm{~min}(\mathrm{~A})$. The $\mathrm{I}_{50}$ value of each sample was compared to the value of batter $(=0)(B)$.

and expressed as the amounts required to attain $50 \%$ inhibition of the reaction between OM and anti OM serum (Fig.1-B). The soluble OM concentrations in cookie samples baked for $2 \mathrm{~min}$ and 6 min were almost the same as in the batter, which faithfully reflected the amount of OM occurring in egg white. The amount of soluble $\mathrm{OM}$ in the cookies was reduced to below one-tenth by baking at $180^{\circ} \mathrm{C}$ for $8 \mathrm{~min}$ or more.

Bread was baked from dough so as to make comparisons between cookie and bread. The PBS soluble fractions were prepared by buffer extraction from both dough and bread baked at $180^{\circ} \mathrm{C}$ for $8 \mathrm{~min}$. The soluble $\mathrm{OM}$ in bread was about $1 / 10000$ as much as that in dough, indicating that soluble OM almost disappeared in the bread (Fig. 2). These results with reference to our previous report show that disulfide exchange occurred between $\mathrm{OM}$ and wheat compounds (Kato et al., 1997). The disappearance of OM in bread may be attributed to the dough formed by kneading.

In cookie making, the watery batter was fully mixed instead of kneading as an additional treatment before baking. This resulted in a disulfide exchange reaction between wheat protein and OM, leading to the loss of soluble OM. The effects of mixing for from zero to $15 \mathrm{~min}$ using a hand mixer $(650 \mathrm{rpm} / \mathrm{min})$ were examined in detail before baking at $180^{\circ} \mathrm{C}$ for $8 \mathrm{~min}$. Zero time of mixing was defined as the point at which all materials were well mixed. The soluble OM in baked cookies was analyzed by ELISA competitive inhibition using anti OM antibody (Fig. 3).
(A)

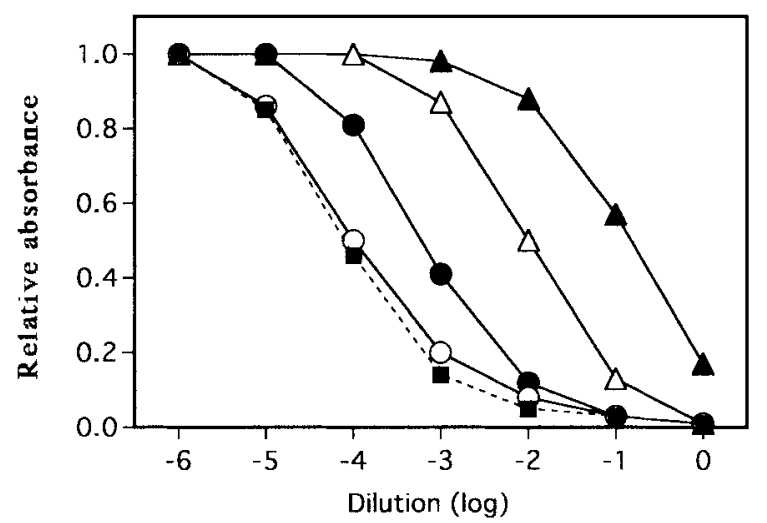

(B)

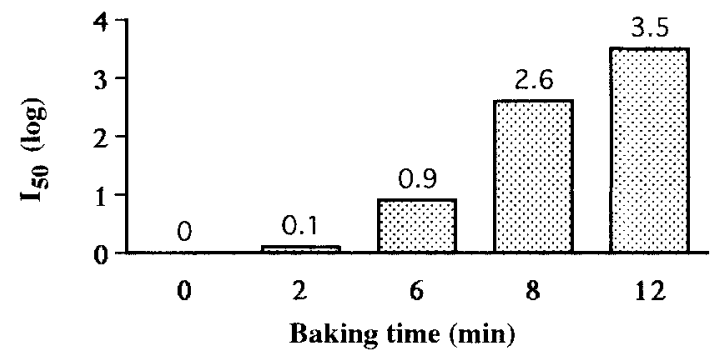

Fig. 4. ELISA competitive inhibition for antigenic OM in the PBS extracts of cookies baked for different times. Batter ( $\boldsymbol{\square})$ after mixing for 15 min was divided into pieces, which were baked at $180^{\circ} \mathrm{C}$ for $2(\circ), 6(\bullet), 8(\triangle)$, or 12 $\min (\Delta)(\mathrm{A})$. The $I_{50}$ value of each sample was compared to the value of batter $(=0)(B)$. The assay procedures for soluble OM are the same as shown in the legend of Fig. 1.

(a) SDS-PAGE

(B) Immunoblotting

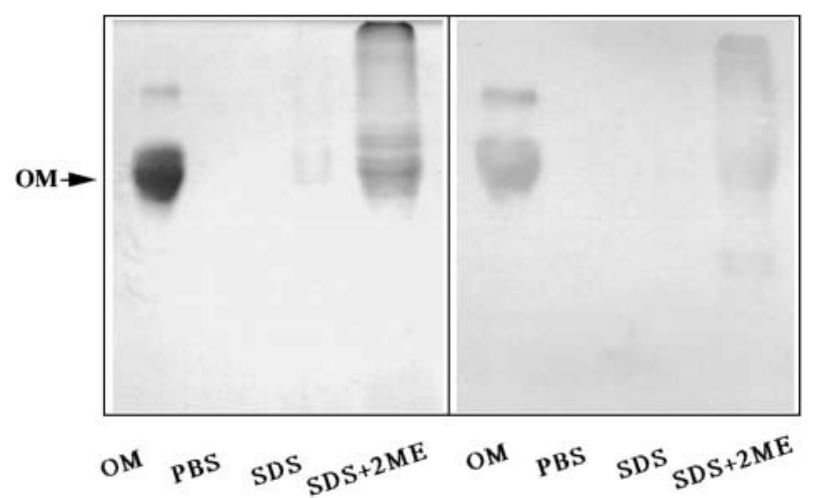

Fig. 5. Separation by SDS-PAGE (A) and immunoblotting (B) of proteins extracted with PBS, SDS or SDS+2-ME from baked cookies. Proteins were extracted from cookies baked at $180^{\circ} \mathrm{C}$ for 12 min after 15 -min mixing using PBS, SDS and SDS+2-ME solutions. Each extract $(10 \mu \mathrm{l})$ or a $10 \mu \mathrm{l}$ solution of authentic OM $(1 \mu \mathrm{g} / \mu \mathrm{l})$ was subjected to SDS-PAGE as usual. The gel sheet and its blotted membrane were stained with CBB and a rabbit anti-OM serum, respectively. SDS-PAGE was carried out using a $12.5 \%$ separating gel and a $4 \%$ stacking gel.

Soluble OM in cookie samples decreased along with mixing time. Moreover, the content of soluble OM in the cookies mixed for 15 min was greater about 400 times than that in batter to attain $50 \%$ inhibition of the reaction between OM and anti OM serum. The amount of soluble OM in the 15 min-mixed cookies 
corresponded to $1 / 40$ of that in the cookies prepared without mixing.

The relationship between baking time at $180^{\circ} \mathrm{C}$ and PBS soluble OM remaining in the cookies baked after 15-min mixing of the batter is shown in Fig. 4. The soluble OM decreased with prolonged baking time, although remaining appreciably in cookies baked from the usual batter without mixing. Meanwhile, the soluble OM in the cookies disappeared when the batter was mixed beforehand for 15 min instead of kneading in breadmaking, and then baked at $180^{\circ} \mathrm{C}$ for $12 \mathrm{~min}$.

Soluble proteins extractable with PBS, SDS or SDS+2-ME from the cookies baked at $180^{\circ} \mathrm{C}$ for 12 min were analyzed by means of SDS-PAGE and immunoblotting (Fig. 5). Several proteins capable of being stained with $\mathrm{CBB}$ were found in the SDS extract, but not in the PBS extract, and also proteins with higher molecular weights were also observed in the SDS+2-ME extract. OM occurring in these extracts was identified by immunoblotting using anti OM serum. OM was undetectable in both PBS- and SDS-extracts as shown in Fig. 5. On the other hand, multiple protein bands with higher and lower molecular weights present in the SDS+2-ME-extract were positive to immunoblotting. Higher molecular bands might be the polymers interacting with wheat proteins, and the immunoblotted lower molecular band was presumed to be a degradation product of the complex of wheat protein and OM by mixing and heat-treatment. This result can be explained by disulfide exchange reactions between wheat gluten and OM leading to insolubilization of an irreversible denaturation of antigenic OM as described previously (Kato et al., 1997; 2000).

Watery batter does not change into dough by mixing for 15 min, although the time is relatively long. Processed wheat flour foods are produced from either dough or batter. The treatment of additional mixing and slightly longer baking is an alternative procedure for making cookies; in this case, however, the taste of the cookies is still almost the same as in the usual way. This procedure can be applied to processed wheat flour foods such as doughnuts and fritters made from the batter with supplemental egg. A study to estimate the metabolic modulation of insoluble $\mathrm{OM}$ in such processed foods as cookies is in progress.

Urisu et al. (1997) recently reported that oral challenge of eggsensitive patients to thermo-coagulated egg white did not induce any allergic response in $21(55 \%)$ of 38 persons who were hypersensitive to raw egg white and that egg white coagulation deprived of soluble protein is much more hypoallergenic than heatdenaturated egg white. These results suggest that heated and insolubilized egg white allergens are clinically hypoallergenic compared with the native and soluble ones. It is very interesting to evaluate the allergenicity of the cookies containing insolubilized OM by clinical tests such as skin prick and oral challenge. If the insolubilized OM has little or no clinical allergenicity, the insolubilization procedure proposed in the present study surely serves as a convenient and useful means of converting hyperallergenic foods to hypoallergenic ones.

Acknowledgment The authors gratefully acknowledge Dr. Tsukasa Matsuda (Nagoya University) for his gifts of purified ovomucoid and rabbit anti-ovomucoid serum.

\section{References}

Engvall, E. and Perlmann, P. (1971). Enzyme-linked immunosorbent assay (ELISA). Quantitative assay of immunoglobulin G. Immunochemistry, 8, 871-874.

Gu, J., Matsuda, T. and Nakamura, R. (1986). Antigenicity of ovomucoid remaining in boiled shell eggs. J. Food Sci., 51, 1448-1450.

Hoffman, D.R. (1983). Immunochemical identification of the allergens in egg white. J. Allergy Clin. Immunol., 71, 481-486.

Kato, Y., Watanabe, H. and Matsuda, T. (1997). Decrease in ovomucoid antigenicity in the processes of breadmaking supplemented with egg white. Food Sci. Technol. Int. Tokyo, 3, 362-365.

Kato, Y., Watanabe, H. and Matsuda, T. (2000). Ovomucoid is insolubilized by heating with wheat gluten but not with milk casein. Biosci. Biotechnol. Biochem., 64, 198-201.

Laemmli, U.K. (1970). Cleavage of structural proteins during the assembly of the head of bacteriophage T4. Nature (London), 227, $680-685$.

Langeland, T. (1982a). A clinical and immunological study on allergy to hen's egg white. II. Antigens in hen's egg white studied by crossed immunoelectrophoresis. Allergy Copenh., 37, 323-333.

Langeland, T. (1982b). A clinical and immunological study on allergy to hen's egg white. III. Allergens in hen's egg white studied by crossed radio immunoelectrophoresis. Allergy Copenh., 37, 521530.

Matsuda, T., Watanabe, K. and Nakamura, R. (1982). Immunochemical studies on thermal denaturation of ovomucoid. Biochim. Biophys. Acta, 707, 121-128.

Matsuda, T., Watanabe, K. and Nakamura, R. (1983). Blocking effect of trypsin associated with ovomucoid on the antibody binding to ovomucoid. J. Biochem., 94, 43-49.

Taylor, S.L. (1980). Food allergy. The enigma and some potential solutions. J. Food Prot., 43, 300-306.

Towbin, H., Steehelin, T. and Gordon, J. (1979). Electrophoretic transfer of proteins from polyacrylamide gels to nitrocellulose sheets: Procedure and some applications. Proc. Natl. Acad. Sci. USA., 76, 4350-4354.

Urisu, A., Ando, H., Morita, Y., Wada, E., Yasaki, T., Yamada, K., Komada, K., Torii, S., Goto, M. and Wakamatsu, T. (1997). Allergenic activity of heated and ovomucoid-depleted egg white. $J$. Allergy Clin. Immunol., 100, 171-176. 